\title{
ASSESSING LANDFILL LEACHATE QUALITY AND LEACHATE TREATMENT EFFICIENCY USING GOOD SAMPLING PRACTICES
}

\author{
Cecilia Öman \\ International Foundations for Science (IFS), Sweden \\ Christian Junestedt \\ Swedish Environmental Research Institute (IVL), Sweden
}

\begin{abstract}
A number of the compounds detected in landfill leachates have proved to be harmful to humans and to the natural environment. As a result, appropriate landfill leachate treatment methods must be developed, with the aim to reduce harmful concentrations of pollutants to levels which do not impose a threat to the natural environment. The complex nature of the leachates makes it difficult to select the most appropriate set of treatment methods for a specific landfill, and the actual efficiency of a treatment plant is measured in situ by comparing the quality of the water entering the plant with the quality of the water leaving the plant. The complex nature of the leachates puts high demands on the sampling, handling of sample before analyses, and analyses, as the character of the sample must not be altered. The demands increase with decreasing concentrations of the targeted compounds ( $\mu \mathrm{g} / 1$ level or less). Despite this, no standard protocols for sampling and handling of leachate samples exist.
\end{abstract}

The purpose of this study was to give examples of good sampling practices. Important aspects to consider during sampling and handling of samples are; i) sampling of nonhomogenized water bodies, ii) contamination, and iii) alterations of samples during collection and storage. It was found that a number of substances are enriched in the surface layer of a water body, why it was concluded that the surface layer is an important matrix to consider, both concerning the presence and the transport of harmful compounds. The risk of contamination during sampling was evaluated with the use of a field water blank, which was handled as a true water sample. It was found that despite careful handling contaminants were found at low concentrations ( $\mu \mathrm{g} / 1$ level) in the field water blank, which indicated a severe risk of contamination during leachate sampling, handling of sample and/or analyses. Also in this study, the alteration of leachate samples during transport and storage was assessed. The results showed that preservation with 0.2 weight-\% sodium azide immediately after sampling and storing at $48 \mathrm{C}$ for a maximum of 
KALMAR ECO-TECH'03

Bioremediation and Leachate Treatment

KALMAR, SWEDEN, November 25-27, 2003

seven days in borosilicate glass bottles, resulted in the lowest loss of organic compounds from the samples.

It has been evident since long that the reported character of sampled landfill leachates varies significantly. The variations can been assumed to sometimes origin from the sampling procedures used.

In conclusion, the choice of sampling, transport, storage, and sample preparation before analyses is more crucial for the outcome of leachate characterisation studies than sometimes conceived.

\section{KEYWORDS}

Landfill leachate quality; Assessment of leachate treatment methods; Good sampling practices; Sampling errors; Non-homogenised water bodies; Adsorption to equipment material; Contamination; Sample conservation; Loss of compounds; Alteration of instable samples.

\section{INTRODUCTION}

Leachates from landfills have been found to contain a complex mixture of a different types of compounds; i) organic compounds, including aromatic compounds, halogenated compounds, phenols, and pesticides, ii) inorganic components, including heavy metals, iii) metal-organic compounds including organic mercury and organic tin, iv) ions including chloride and ammonium, and $v$ ) oxygen-consuming dissolved organic matter [i, ii, iii, iv , $v$, and others]. A number of the identified compounds in landfill leachates have proved to be harmful to humans and the natural environment, and the leachates may pose a threat if they are spread into the environment.

As a result of the harmful character of landfill leachates appropriate landfill leachate treatment methods must be developed. Before the treated water is let out into the natural environment the concentration of each compound must be below the concentration which is harmful to the receiving environment. The complex nature of the leachates makes it difficult to select the most appropriate set of treatment methods for a specific landfill. Harmful compounds in the leachate must be identified, and each harmful compound must bee treated according to their own chemical, physical and biological character in order to reduce the concentration of that specific compound to a level which is acceptable [vi].

The efficiency of landfill leachate treatment methods is assessed in situ by sampling and analyzing the water entering the plant, and compare its content with the water leaving the plant. This can be done for the treatment plant as a whole, or for each treatment step. Important steps in the assessment procedure are the sampling, the handling of samples, and the chemical analyses. The complex nature of the leachates creates high demands on the methods used and a high level of accuracy is needed. The demands increase when the concentrations of the harmful compounds are low. Harmful compounds, such as pesticides, polyaromatic hydrocarbons, chlorinated compounds and organic mercury, 
have been found at low concentrations ( $\mu \mathrm{g} / 1$ - level or less). Harmful compounds at low concentrations must not be neglected until future toxicological and ecotoxicologial research have indicated which concentration levels are of interest.

It has been evident since long that the reported character of sampled landfill leachates varies significantly [vii]. The variation is due to the different types of deposited wastes, different transitions stages of the landfill, and different landfill constructions. The significant variations can been assumed to also origin from different sampling and analytical procedures used in the different studies. Despite this, no standard protocols for sampling and handling of leachate samples exist.

The aim of this study was to correlate sampling and sampling handling methods to the character of landfill leachates, and to give recommendations for good sampling practice. The conclusions and recommendations are valid also for other types of complex environmental samples.

\section{SOURCES OF ERRORS DURING SAMPLING AND HANDLING OF SAMPLES}

Due to the complex nature of landfill leachates, sampling and the handling of samples may alter its content, which would results in incorrect characterisation of the leachate quality. Sources of errors include; adsorption of compounds on glassware and other materials, non- representative sampling from non-homogenized water bodies, contamination, and alteration of samples due to sample instability.

\section{ADSORPTION TO GLASSWARE AND OTHER MATERIALS}

Hydrophobic organic compounds and metals may be adsorbed on to the walls or the cap of the sampling, transport or storage equipment. Trace concentrations of metals have been found to sorb to glass material. Hydrophobic pesticides have been found to be readily adsorbed on glass and PTFE (polytetrafluoroethylene, Teflon) when pure water are spiked with the compounds [viii, ix]. Losses in the order of $10-30 \%$, and even up to $100 \%$, have been reported. However, when organic material such as organic sediment or organic waste material was introduced into the clean water, the losses of organic compounds due to adsorption to the equipment were reduced from severe to negligible (less than $1 \%$ ), as the compounds were then sorbed to the organic material instead [x].

\section{NON-REPRESENTATIVE SAMPLING FROM NON-HOMOGENISED WATER BODIES}

Compounds in the leachates can be present simultaneously in different phases of a water body. The compounds can be; i) truly dissolved in water, ii) sorbed to suspended particles, such as particulate organic matter or minerals, iii) bound to dissolved organic matter, including humic and fulvic acids and other colloids, iv) be present as metalcomplexes [xi], or v) enriched in the surface layer [16]. As a consequence, the concentration of compounds measured in leachate samples depend on the amount of the different phases presented in the sample, and the handling of the sample. When compounds are sorbed, they can be transported in the body of waters, and this has 
implications on the transportation through treatment plants and on the transport in the natural environment.

A key question when determining the character of leachate samples is therefore, whether it is of interest to determine the presence of compounds in all five phases, together or separately, or only in some phases. The sampling and chemical analyses must be performed accordingly. Future toxicological and ecotoxicologial research will indicate to which extent sampling and analytical method development should focus more on water soluble compounds, on the particle and colloid bound [xii], or on the surface layer.

\subsection{Colloids and suspended particles}

The content of suspended particles and colloidal matter in a sample depends to a large extent on the sampling technique used. When samples are obtained from ground water monitoring wells, a high pumping rate has been found to increase the colloid content of the sample[xiii].The sorption of organic compounds to dissolved organic matter in a water sample has been found to sometimes depend on the $\mathrm{pH}$-level of the sample. The $\mathrm{K}_{\mathrm{oc}}$ of atrazine was found to four-fold in environmental water samples, when the $\mathrm{pH}$-level was increased from $\mathrm{pH} 5$ to $\mathrm{pH} 8$ [11]. Moreover, colloids have been found to have high affinity for metals [xiv], thus the concentration of metals measured in leachate samples is dependent on the amount of colloidal matter presented.

\subsection{Surface layer}

Besides colloids and suspended particles it has been found that the surface layer of an open water body can contain increased concentrations of certain compounds. A variety of biological, chemical and physical processes take place in the surface layer, which affects its content and distribution. The surface layer is built from different sub-fractions; the nano-layer, the micro-layer and the milli-layer [xv]. The nano-layer can be enriched with detergents, while the micro layer is generally enriched with particles and microorganisms.

The surface micro-layer of a leachate pond was examined at a Swedish landfill site [xvi]. The layer was sampled with PTFE plates $(\varnothing 132 \mathrm{~mm})$. The PTFE plates had been pretreated with a mixture of sodium hydroxide and ammonia, which created a coating with very small holes on one side of the plates. During the sampling, capillary forces attaches the surface micro layer on to the plate. The collected surface micro layer was then described by the use of an enrichment factor (Ef). Ef provides a comparison between the concentration in the surface micro layer and the underlying bulk water. The results indicate that a number of substances were enriched in the surface micro-layer, or were even detectable only in the surface micro-layer. Lead was enriched by a factor of 59 in the surface micro layer, compared to the bulk water. Pentachlorphenol (PCP) was enriched 68 times in the micro-layer. Lindan could not be detected at all in the bulk water, but only in the micro-layer. The concentration of Lindane in the micro-layer was $10.4 \mathrm{ng} /$ liter. The results show that the surface micro-layer is an important matrix in landfill leachate ponds, both concerning the presence and the transport of harmful compounds. 


\section{CONTAMINATION}

Samples can become contaminated through a variety of reasons including; i) improper cleaning of the sampler or sample container, ii) migration of compounds from the material constituting the sampler or sample container, iii) through the introduction of contaminated material, such as unclean preservation agents or dust from the surrounding air, or iv) through inappropriate sampling, such as collecting samples downstream a polluting source.

The risk for contamination during sampling was evaluated in this study by using a field water blank, which was treated in the field as a true sample in all respects. The sampling bottles were made of borosilicate glass, in order not to contaminate the sample. The bottles were thoroughly rinsed by; washing with detergent, rinsing with tap water and distilled water, drying (up side down), and then coating them with aluminium foil and heating them for 1 hour at $4008 \mathrm{C}$. FEP (fluorinated ethylene propylene) coated caps were washed, rinsed and foiled with pre-heated aluminium foil (1 hour at $4008 \mathrm{C}$ ). The treated bottles were filled with pollutant free Milli-Q-water, leaving no air space, and were then capped prior to the transport to a Swedish landfill site. At the landfill site the Milli-Qwater was poured into other borosilicate bottles, which had been rinsed with the same procedure. The samples were transported at $48 \mathrm{C}$ to the laboratory within 6 hours, $1 / 3$ of the water volume was discarded, and the bottles were frozen. Thawing was performed at $4^{\circ} \mathrm{C}$ overnight, keeping the bottles up side down in order to prevent loss of volatile compounds through the screw cap. The samples were analysed immediately after.

It was found from the results that out of 93 compounds, two phthalatic esters and fenantrene could be detected at very low concentrations (Table 1). This showed that, despite thorough treatment of equipment and samples, there is still a risk for contamination during sampling and/or the analyses of leachate samples. Random appearances of phthalates and other contaminants make the use of method water blanks and field water blanks the key parameter for the quality assurance.

Table 1. Results from chemical analysis of field water blanks.

\begin{tabular}{lcccc}
\hline $\begin{array}{l}\text { Group of compounds } \\
\text { analysed }\end{array}$ & $\begin{array}{c}\text { Number of } \\
\text { compounds }\end{array}$ & $\begin{array}{c}\text { Detection limit, Compounds found } \\
\mu \mathrm{g} / \mathrm{l}\end{array}$ & $\begin{array}{c}\text { Concentrations } \\
\text { found, } \\
\mu \mathrm{g} / \mathrm{l}\end{array}$ \\
\hline $\begin{array}{l}\text { Chlorinated volatile } \\
\text { hydrocarbons }\end{array}$ & 14 & $0.1-1.0$ & - & \\
$\begin{array}{l}\text { Monocyclic aromatic } \\
\text { compounds }\end{array}$ & 4 & 0.1 & - & \\
$\begin{array}{l}\text { Phenols and } \\
\text { alkylated phenols }\end{array}$ & 3 & $0 . d$ & - & 0.03 \\
$\begin{array}{l}\text { Polycyclic aromatic } \\
\text { compounds }\end{array}$ & 16 & $0.001-0.1$ & Fenantrene & \\
\end{tabular}


Phthalatic esters

Chlorinated benzenes

Chlorinated phenols

Phenoxy acids

Organic tin
9

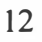

21

8

6
Diethyl phthalate

Di-isobutyl

phthalate

- The compounds have been analysed but were not detected at concentrations above the detection limit.

The results from this study are in accordance with previously reported results. Phthalatic esters have been found to easily contaminate environmental water samples [xvii]. Sources of contamination have been identified as indoor and outdoor surroundings, as well as the material coming into contact with the sample. Flooring, wall painting, and wires are made of plastic and rubber material containing phthalates. From these materials the phthalates, often di-butyl phthalate (DBP) and di-2-ethylhexyl phthalate (DEHP), migrate directly or via air to the laboratory chemicals [xviii], solvents and equipment. This causes substantial contamination of samples and analytical problems, but can be overcome by protecting chemicals, solvents, equipment and the samples from air and dust by means of aluminium foil. Contaminants in solvents must be eliminated and, the solvents must be checked for contaminants before use. Strict cleaning procedure of all glass and metal having contact with the samples must be performed including washing with detergent and rinse with tap water and the distilled water, heating at $4008 \mathrm{C}$ during $1 \mathrm{~h}$, and wrapping in preheated aluminium-foil [17]. Equipment made of PTFE and Plexiglas is washed with detergent, rinsed with tap water, distilled water and acetone, methanol or 2-propanol. After drying the material is rinsed with hexane and wrapped in preheated aluminium foil. Moreover, occurrences of phthalates are frequently artefacts, since laboratory and sampling equipment of plastics often contain phthalates. Therefore, devices coming into contact wit the samples must not contain plastic and rubber parts. Random appearances of phthalates and other contaminants make the use of method water blanks and field water blanks the key parameter for the quality assurance.

\section{ALTERATION OF SAMPLE}

A number of processes may change the content of a sample during the processes of sampling, sample handling, and analyses, due to the inherent instability of the sample itself. The changes are caused by chemical, biological and physical processes and include for example; evaporation, biological degradation, redox reactions, complexations and sorption-desorption processes.

\subsection{Sampling}

It is generally recommended to use spot samples for the collection of unstable samples [xix]. Spot samples are discrete samples, usually collected manually but which can also be collected automatically. Moreover, it is recommended to collect instable samples during as short time period as possible. Concerning the collection of water samples for 
KALMAR ECO-TECH'03

Bioremediation and Leachate Treatment

KALMAR, SWEDEN, November 25-27, 2003

the analyses of metals at anaerobic sites, it can be recommended to sample under anaerobic conditions until the sample is preserved, as the solubility of certain metals varies with the level of oxidation.

\subsection{Transport and storage}

In order to study the alteration of leachate samples during transport and storage, different transport and storage methods were compared and evaluated. Six leachate samples were collected at one occasion from a Swedish leachate pond. The samples were preserved and stored by six different methods including; storage at $4^{\circ} \mathrm{C}$ in borosilicate glass bottles during 2 and 7 days, addition of the preservative agent sodium azide $\left(\mathrm{NaN}_{3}\right)$ and no such addition, storage at $-18^{\circ} \mathrm{C}$ in borosilicate glass with airspace, and storage at $-18^{\circ} \mathrm{C}$ in PTFE bottles without airspace (Table 2). Prior to sampling, the borosilicate bottles were thoroughly rinsed, heated to $400^{\circ} \mathrm{C}$, and foiled with aluminium foil, as were previously described for field water blanks. The PTFE bottles were thoroughly washed with detergent, rinsed with tap water and distilled water, rinsed with acetone, heated to $150^{\circ} \mathrm{C}$, and foiled with pre-heated aluminium foil. Due to the low temperature tolerance of the PTFE material, it cannot be heated to $400^{\circ} \mathrm{C}$, as is recommended for borosilicate bottles. At the landfill site, all bottles were filled with leachate samples, leaving no air space; except for the borosilicate bottles that were to be frozen, these were filled only to $2 / 3$ of the volume. In all other respects, identical sampling techniques were used for all samples. To certain bottles 0.2 weight-\% sodium azide were added immediately after sampling. The bottles were caped with pre-treated and aluminium foiled PTFE coated caps, and were transported, in darkness and at $4^{\circ} \mathrm{C}$, to the laboratory within 6 hours. At the laboratory the samples were immediately stored, also in darkness, according to the six different methods, before they were analysed. In addition, frozen samples were thawed at $4^{\circ} \mathrm{C}$, overnight and up side down, before being analysed.

Each sample was analysed for eight monoaromatic hydrocarbons, naphthalene, and dichlorobenzene. The results were interpreted by calculating the precision of the analytical results for the different methods; as the relative population standard deviation (RSD). Compounds that were not detected were given half the value of the detection limit. When the results varied within the limits of the precision for the analytical methods itself, the results were interpreted as implying no significant variation between the storing methods. The precision values of the analytical methods were; $9 \%$ for monoaromatic hydrocarbons, $5-10 \%$ for naphthalene, and $10 \%$ for dichlorobenzene. When the concentrations were less than 5 times the detection limit, the precision sometimes increase to $30-50 \%$.

The results from this study indicated that freezing of leachate samples caused significant losses of certain organic compounds. The losses of compounds were severe both when freezing in borosilicate glass bottles after having filled the bottle to $2 / 3$ of its volume (18$61 \%$ ), and when freezing in PTFE bottles without any air space (36-65\%). Significant losses were also causes by storing the samples in $4^{\circ} \mathrm{C}$ for seven days without the addition of any preservative agent (26-91\%), with the exception of dichlorobenzene for which the loss was insignificant. Moreover, the results indicated insignificant losses when samples were preserved with 0.2 weight $\%$ sodium azide immediately after sampling, and stored 
KALMAR ECO-TECH'03

Bioremediation and Leachate Treatment

KALMAR, SWEDEN, November 25-27, 2003

at $48 \mathrm{C}$ for a maximum of seven days in borosilicate glass bottles. These results were in agreement with previous results showing that sodium azide suppressed the biological activity in a waste sample [9]. The results also indicated that if the storage time was reduced to less than 2 days, the preservative agent could be excluded.

Table 2. Compilation of results from comparing six methods of storage leachate samples prior to analysis of organic compounds. All units are $\mu \mathrm{g} / \mathrm{l}$, except for the precision (relative population standard deviation, RSD) and loss of compounds, which are in weight $\%$.

\begin{tabular}{|c|c|c|c|c|c|c|c|c|c|c|c|}
\hline & $\begin{array}{l}\text { Detectio } \\
\text { limit }\end{array}$ & & & & & & & $\frac{\mathrm{RSD}}{\underline{\%}}$ & & Loss, ${ }^{\circ}$ & \\
\hline Material in bottle & & Glass & Glass & Glass & Glass & Glass & PTFE & & & & \\
\hline Temperature & & $48 \mathrm{C}$ & $48 \mathrm{C}$ & $48 \mathrm{C}$ & $48 \mathrm{C}$ & $-188 \mathrm{C}$ & $-18^{\circ} \mathrm{C}$ & & & & \\
\hline Storing period & & 2 days & 2 days & 7 days & 7 days & & & & & & \\
\hline Preservative & & none & $\mathrm{NaN}_{3}$ & none & $\mathrm{NaN}_{3}$ & none & none & & & & \\
\hline $\begin{array}{l}\text { Parameters / } \\
\text { Sample name }\end{array}$ & & $\mathrm{A}$ & B & $\mathrm{C}$ & $\mathrm{D}$ & E & $\mathrm{F}$ & $\begin{array}{c}\mathrm{A}, \mathrm{BB} \\
\mathrm{D}\end{array}$ & C & $\mathrm{E}$ & $\mathrm{F}$ \\
\hline \multicolumn{12}{|c|}{$\begin{array}{l}\text { Monocyclic aromatic } \\
\text { compounds }\end{array}$} \\
\hline Benzene & 0.2 & 0.22 & 0.23 & - & 0.39 & 0.23 & 0.18 & 28 & $>64$ & 18 & 36 \\
\hline Toluene & 0.2 & 1.0 & 1.0 & - & 1.2 & 0.71 & 0.54 & 8.8 & $>91$ & 33 & 49 \\
\hline Ethyl benzene & 0.2 & 2.2 & 2.4 & - & 2.5 & 1.6 & 1.2 & 5.3 & $>96$ & 32 & 49 \\
\hline Sum xylenes & 0.2 & 7.7 & 7.9 & 2.6 & 8.4 & 5.5 & 4.1 & 3.7 & 68 & 31 & 49 \\
\hline Iso-propylbenzene & 0.2 & 0.2 & 0.21 & - & 0.23 & 0.15 & 0.11 & 5.8 & $>53$ & 30 & 48 \\
\hline n-Propylbenzene & 0.2 & 0.31 & 0.35 & - & 0.2 & 0.13 & 0.10 & 22 & $>65$ & 55 & 65 \\
\hline $\begin{array}{l}1,3,5- \\
\text { Trimethylbenzene }\end{array}$ & 0.2 & 0.30 & 0.30 & 0.23 & 0.33 & 0.22 & 0.17 & 4.6 & 26 & 29 & 45 \\
\hline $\begin{array}{l}1,2,4- \\
\text { Trimethylbenzene } \\
\text { Polycyclic aromatic } \\
\text { compound }\end{array}$ & 0.2 & 0.88 & 0.93 & 0.17 & 1.1 & 0.72 & 0.56 & 9.7 & 82 & 26 & 42 \\
\hline Naphthalene & 0.1 & 0.12 & 0.13 & - & 0.13 & - & - & 3.7 & $>61$ & 61 & 61 \\
\hline \multicolumn{12}{|l|}{$\begin{array}{l}\text { Chlorinated } \\
\text { benzene }\end{array}$} \\
\hline $\begin{array}{l}1,4- \\
\text { Dichlorobenzene }\end{array}$ & 0.05 & 0.19 & 0.19 & 0.19 & 0.20 & 0.14 & 0.1 & 2.4 & 1.7 & 28 & 48 \\
\hline
\end{tabular}

- The compounds have been analysed but were not detected at concentrations above the detection limit. 


\section{QUALITY ASSURANCE}

Due to the variety of random errors which can alter the content of a sample, it is necessary to include quality assurance components in sampling programmes. Quality assurance during sampling includes replicates, field blanks, and spiked samples [xx]. Replicate quality control samples are used to assess the random errors associated with different levels of sampling processes, including the sampling variance, transport variance and the analytical variance. Field blank samples consist of reagent water in a sample bottle, which is treated in the field as a true sample in all respects, and can be used to identify errors relating to contamination of sampling containers and the sampling process. Spiked samples, either clean water samples or environmental samples, can be used to detect errors due to sample instability, including loss of compounds by volatilisation, adsorption and chemical and biological transformation.

The quality assurance components should take into consideration all types of compounds included in the characterisation of the samples, as well as all sample matrixes, such as particles and surface layers. Unfortunately, in actual practice it is often not feasible to include all compounds; but it can then be recommended to include compounds representing a range of character including; evaporation, sorption, and degradation in the quality assurance studies [xxi].

\section{CONCLUSIONS}

In conclusion, the choice of sampling, transport, storage, and sample preparation methods are crucial for the outcome of a leachate characterisation study. It was found for example that;

- Certain compounds tend to be enriched in surface micro-layers in landfill leachate ponds, why this matrix is important to consider, both concerning the presence and the transport of compounds.

- Careful handling of the leachate samples is crucial for the reduction of sample contamination. Despite careful rinsing and sampling, field water blanks were still contaminated in this study by two phthalatic esters and one aromatic compound.

The selection of appropriate methods for the transport and storage of samples are crucial for minimising losses of organic compounds. Preservation of leachate samples with 0.2 weight $\%$ sodium azide prior to storing at $48 \mathrm{C}$ for 7 days, reduced the loss of organic compounds in comparison with storing at $48 \mathrm{C}$ for 7 days without preservative, freezing in half-full glass bottles, or freezing in PTFE bottles.

As a consequence, it was concluded that in order to minimize alterations of samples during collection and storage, sampling procedures should be outlined with a i) minimum of steps, ii) using a minimum amount of equipment, glassware, solvents and chemicals, and iii) include a minimum amount of time. Quality assurance during sampling should include replicates, field blanks, and spiked samples. 


\section{ACKNOWLEDGMENTS}

The Swedish Environmental Protection Agency and a number of Swedish Landfill companies are gratefully acknowledged for supporting this project both financially and with support during field studies. The International Foundation of Science is acknowledged for supporting the preparation of this paper.

\section{REFERENCES}

[i] Öman C. and Hynning P.-A., 1993, Identification of organic compounds in municipal landfill lechates. Environ. Pollut., 20, 265-271.

[ii] Öman, C., Bengtsson, $\AA$. and Rosqvist, R., 1999, Changes with depth and with time of leachates from a pilot-scale landfill Proceedings of the Seventh International Landfill Symposium, Cagliary, Italy.

[iii] Öman, C. and Rosqvist, H., 1999, Transport fate of organic compounds with water through landfills, Water Res. 33, 2247-2254

[iv] Christensen T. H. , Kjeldsen P., Bjerg P.L., Jensen D.L., Christensen J.B., Baun A. Albrechtsen H-J and Heron G., 2001, Appl. Geochem., 16, 659-718.

[v] Kjeldsen, P. Barlaz, M.A., Rooker, A.P., Baun, A., Ledin, A., and Christensen T.H., 2002, Present and long-term composition of MSW landfill leachate: A review. Crit. Rev. in Environ. Sci. Technol. 32 (4), 297-336

[vi] Öman, C., 2000, Evaluation of leachate treatment methods in perspective of the character of specific organic compounds. Proceedings of The 1st Intercontinental Landfill Research Symposium. Luleå University, Sweden.

[vii] Öman C. ,1993, Identifierade organiska föreningar i lakvatten från avfallsupplag - en litteratursammanställning. Proceedings från Symposium om svensk upplagsforskning, Luleå, 33-44

[viii] House, W.A., Ziqing, Ou, 1992, Chemophere, 24, 819.

[ix] Öman, C., 1998, An automated experimental equipment for studying the fate of organic compounds in landfills. Intern. J. Environ. Anal. Chem., 71, 73-85.

[x] Grathwohl, P., 1990, Environ. Sici. Technol., 24, 1687-1693

[xi] Sigleo, A.C., Means, J.C., 1990, Rev. Environ. Contam. Tox.,112, 123.

[xii] Åkerblom, M., 1995, Extraction and cleanup, in Analyses of pesticides in ground and surface - Water I, Ed. Stan H.-J. Chemistry and Plant protection, SpringerVerlag Berlin Heidelberg, Germany, 21-66.

[xiii] Backhaus, D.A., Ryan, J.N., Groher, D.M., MacFarlane, J.K. and Gschwend, P.M., 1993, Sampling colloids and colloid-associated contaminants in ground water.Ground Water, 31, 466-479 DOI: https://doi.org/10.1111/j.1745-6584.1993.tb01849.x

[xiv] Gounaris,V., Anderson, P.R., and Holsen, T.M., 1993, Characteristics and environmental significance of colloids in landfill leachate, Environ. Sci. Technol., 27, 1381. DOI: https://doi.org/ 10.1021/es00044a013

[xv] Knulst, J.C., Backlund, P., Hessen, D.O., Riise, G., and Södergren, A., 1997, Response of surface micro-layers to artifical acid precipitation in a meso-humic lake in Norway. Water Res, 13, 2177-86

DOI: https://doi.org/10.1016/S0043-1354(97)00061-4

[xvi] Junested, J.,in preparation, Contaminats present in the surface layer of a landfill leachate pond 
[xvii] Parkman, H. and Remberger, M., 1995, Phthalates in Swedish sediments. Swedech Environmental Research Institute B-1167, Stockholm, Sweden.

[xviii] Andersen, K.S. and Lam, J., 1979, Chromatography, 169, 101-106.

[xix] ISO 5667-2;1991(E), Internal Standard- Water quality - sampling, part 2: Guidance sampling techniques. International Organisation of Standardization, Genève, Switzerland

[xx] ISO 5667-14;1998 (E), Internal Standard- Water quality - sampling, part 14: Guidance on quality assurance of environmental water sampling and handling. International Organisation of Standardization, Genève, Switzerland

[xxi] Öman, C., 2001, Comparision between the predicted fate of organic compounds in landfills and the actual emissions. Environ. Sci. Techn., 35, 232-239

DOI: https://doi.org/10.1021/es9812599 
KALMAR ECO-TECH'03

Bioremediation and Leachate Treatment

KALMAR, SWEDEN, November 25-27, 2003 